\title{
LAS VICISITUDES DE LA EMANCIPACIÓN: LA TEORÍA DEL ESTADO DE BOAVENTURA DE SOUSA SANTOS ${ }^{1}$
}

\author{
JAVIER MARTÍNEZ CONTRERAS \\ Universidad de Deusto
}

«Los siervos, si falta el poder de sus amos, nada quieren hacer ni cumplir con lo justo, que Zeus, el tonante, arrebata a cada hombre la mitad de su areté desde el día que en él hace presa la vil servidumbre.»

(Odisea, 17, 320ss)

«¿Cuál es la gran tarea de nuestro tiempo?

[...] Es la emancipación de todo el mundo,

en especial de Europa, que se ha hecho mayor de edad y que ahora se libera de los rígidos andadores de los privilegiados,

la aristocracia»

(Heinrich Heine)

\begin{abstract}
RESUMEN: Uno de los autores más relevantes en el análisis crítico de las derivas actuales de nuestras sociedades es el portugués Boaventura de Sousa Santos. Si bien no desarrolla directamente una teoría del Estado, en su trabajo desarrolla un análisis pormenorizado de la realización del proyecto político de la modernidad, que sistemáticamente ha incumplido la promesa de emancipación que lo fundamentó y le dio legitimidad. En este artículo rastreamos los hitos del análisis de este autor así como las propuestas de refundación del Estado desde la clave de la tensión constitutiva entre emancipación y regulación.
\end{abstract}

PALABRAS CLAVE: Boaventura de Sousa Santos, estado, democracia, emancipación.

\section{The vicissitudes of Emancipation: Boaventura de Sousa Santos' theory of the State}

\begin{abstract}
One of the most significant authors in the critical analysis of the present courses of our societies is the Portuguese Boaventura de Sousa Santos. Although he is not developing a specific theory of the State, his work offers a detailed analysis of the fulfillment of the political project of the modernity. This project has systematically broken the Emancipation promise that provides its foundation and legitimacy. This paper aims to track the landmarks of this author's analysis as well as his proposals to refund newly the State bearing the constitutive tension between emancipation and regulation.
\end{abstract}

KEY WORDS: Boaventura de Sousa Santos, state, democracy, emancipation.

1 El presente texto se ha elaborado dentro del marco del Proyecto de Investigación Poder Público y Empresa en un contexto multinivel y transnacional (Gobierno Vasco IT607-13 / Deusto R2013) de la Facultad de Derecho de la Universidad de Deusto. 


\section{Prenotanda}

Quizá convenga comenzar justificando la elección de este autor en un contexto referido a la necesidad de pensar el Estado desde claves que nos permitan afrontar convenientemente el desafío doble de mantenerlo en términos democráticos en un mundo globalizado ${ }^{2}$. En la actual escena del pensamiento español, la obra de Boaventura de Sousa Santos no es ocasión habitual de debate ni tampoco referencia frecuente. Sí lo es, y con importantes resonancias, en América Latina y en algunos países europeos, como muestra la diversidad de procedencias de los estudiantes y académicos que llenan el Centro de Estudos Sociais de la Universidad de Coímbra fundado por él. También se perciben ciertos ecos frecuentes de su obra y pensamiento en prensa crítica internacional ${ }^{3}$.

La obra de este sociólogo portugués probablemente pueda ser calificada sin ambages como uno de los análisis críticos contemporáneos de mayor agudeza, capacidad de penetración y más amplios en referencias del panorama actual de esta disciplina. Y lo es porque en él se dan cita un conocimiento consistente y generoso de la tradición de pensamiento político moderno, con el conocimiento de primera mano de eso que en un amplio gesto lingüístico podemos llamar «el sur», especialmente lo tocante a América Latina y a buena parte de África. Ciertamente, la tradición colonial portuguesa, o al menos la sostenida relación con las antiguas colonias, no deja de hacer valer en esto su peso histórico.

No sin razón podría objetarse que no hay en la obra de Boaventura de Sousa Santos una teoría del Estado como tal; pero no es menos cierto que una consideración de esa índole también sería un juicio con tintes de precipitación. El caso es que la reflexión y observaciones de este autor en torno a las limitaciones efectivas del proyecto político de la modernidad europea en el actual contexto global contienen elementos de una valía que no es posible, conociéndolos, dejar de incorporarlos a una reflexión sobre el Estado que tiene mucho que aprender del amplio mundo de experiencias y observaciones políticas anidadas en el afuera de los habituales circuitos hegemónicos por los que suelen discurrir e intercambiarse tales constructos. No se trata de una nota exótica, sino del descubrimiento de una suerte de terra incognita en la que hay mucho por pensar, retomar y asimilar ${ }^{4}$. Y más que lugar de exploración en términos

2 Casi obligada resulta aquí la referencia a DANI RoDRIK (2011), La paradoja de la globalización. Democracia y futuro de la economía mundial. Barcelona, Antoni Bosch, quien en el capítulo 9 del texto, titulado «El trilema político de la economía mundial» proponía que entre Estado, Hiperglobalización y Democracia sólo podíamos escoger dos, y parecía decantarse por un tándem en el que una globalización inteligente redundaba en una mejor democracia nacional, poniendo en segundo plano al Estado, cuando menos. En sus últimos trabajos Rodrik corrige esta posición recuperando el papel central de esa institución política que, a pesar de todo, parece irrenunciable.

3 Buena cuenta de ello se da en la página web personal del autor, con textos y entrevistas en prensa. Véase http://www.boaventuradesousasantos.pt/pages/pt/homepage.php

4 Es de importancia capital en la obra de este autor su texto titulado Hacia una sociología de las ausencias y una sociología de las emergencias, entre otros lugares, recogido en 
coloniales, se trata de recuperar la visibilidad de lo que el proyecto moderno declaró invisible y expulsó del universo de lo existente en el ejercicio de lo que nuestro autor llama el pensamiento abismal ${ }^{5}$.

No obstante, la invitación y el desafío que suponen la obra de Boaventura de Sousa Santos tampoco están exentos de algunas dificultades de cierto alcance. La primera de la que es necesario hacerse cargo es que estamos ante un autor que todavía está en proceso de elaboración de su pensamiento, lo cual convierte toda exposición en una aproximación más o menos acertada (o desacertada) a una teoría todavía en desarrollo, con rasgos bastante asentados pero sin la compleción de su figura. En consecuencia, conviene advertir de la necesidad de no olvidar que lo que aquí se dice tiene un carácter provisional, tentativo, si bien, no obstante, - como espero se verá - suficiente como para dar cuenta ya de pistas valiosas para considerar críticamente el proceso de cambio paradigmático en el que Boaventura de Sousa Santos nos sitúa, y con él y desde su lectura, proyectar, no sin titubeos, lo que pueda ser un futuro democrático deseable a escala global.

La segunda dificultad importante es el modo en el que se ha construido y se está construyendo el pensamiento de este autor. Sus materiales están dispersos en artículos y libros diferentes estructurados siguiendo un patrón modular, me atrevería a decir. Esto tiene la ventaja de proporcionar una flexibilidad enorme y muy conveniente a una teoría que aspira a superar consciente y deliberadamente la distancia entre reflexión y praxis; pero también dificulta la labor de síntesis por la repetición de las referencias que incluyen los mismos o muy parecidos textos, con cambios apenas de matiz en algunos casos. Así, la obra de este autor genera una cierta sensación de estar ante un palimpsesto, dejando abierta siempre la duda de si el lector habrá tenido en cuenta todo lo que era menester haber leído para el tema de estudio escogido. De nuevo, el carácter incompleto de la obra justifica el carácter tentativo, abierto, del intento de exposición más o menos ordenada o sistemática que obliga a un primer trabajo de identificación topológica de índole casi detectivesca, completado a su vez por una presentación lineal que de hecho decide ignorar el perfil fragmentario y modular del proceso de creación y comparecencia de las ideas que nos intere$\operatorname{san}^{6}$. Toda «reconstrucción» es objetable, si bien creemos haber respetado los

Boaventura de Sousa Santos (2011), El milenio huérfano. Ensayos para una nueva cultura política. Madrid, Trotta, pp. 89-130.

5 Cf. Boaventura de Sousa Santos (2010), Descolonizar el saber, reinventar el poder. Montevideo, Trilce, Cap 2 «Más allá del pensamiento abismal: de las líneas globales a una ecología de saberes. pp. 29-62.

6 Para lo que sigue, y aunque aparecerán otros textos complementarios citados cuando se requiera, he tenido en cuenta las siguientes obras de BoAventura DE Sousa SANTos (1991) "Subjectividade, Cidadania e Emancipaçao» en Revista Crítica de Ciencias Sociais $\mathrm{n}^{\circ} 32$ 135-191; (2003) Crítica de la Razón Indolente Bilbao, Desclee de Brouwer; (2003) La caída del Ángelus Novus: Ensayos para una nueva teoría social y una nueva práctica política. Bogotá, ILSA; (2008) Reinventar la democracia. Reinventar el Estado. Madrid, SeQuitur; (2009) Pensar el Estado y la sociedad: desafíos actuales Buenos Aires, Clacso/WaLdhuter; (2010) Refundación 
ejes centrales que permiten articular a su autor el despliegue cromático de su pensamiento aplicándolo en diferentes contextos y ocasiones con notable éxito analítico.

Con independencia de las dificultades reseñadas, es posible identificar un eje transversal que articula todas las ideas —en su mayoría de índole analítica y basadas en trabajos de campo- desgranadas en los textos que acabamos de mencionar. Ese eje vertebrador, que el propio autor subraya en diferentes lugares de su obra como su tesis hermenéutica fundamental del proyecto político moderno, es la tensión entre lo instituyente y lo instituido o, en términos más idiosincráticos, la tensión entre emancipación y regulación ${ }^{7}$.

Boaventura de Sousa Santos elige esta tensión al menos por dos razones: una metodológica y otra teórica. En cuanto a la primera, es obvio que si se escoge el marco de la Teoría crítica como referente instrumental y conceptual para el análisis socio-político, entonces una de las tareas ineludibles es la identificación de las tensiones dialécticas que dan cuenta de una realidad en sí misma ya contradictoria. Convengamos que el topos teórico y metodológico desde y con el que se piensa es, como todos, discutible, pero no lo es ni la consideración de la realidad social y política como contradictoria ni, en consecuencia, su tratamiento dialéctico. En este punto se antoja que el acuerdo, más que posible, pareciera insoslayable.

En cuanto a la razón teórica, cualquier mirada sobre el pensamiento político de los siglos XVII, XVIII y XIX, así como una lectura de los acontecimientos históricos que lo alimentaron y espolearon, manifiestan dos constantes contradictorias cuya síntesis no hemos logrado —ni es previsible lograr en términos de resolución al menos-: la revolución y la reforma como instrumentos de cambio, de modificación y de transformación, y las instituciones y sus inercias, entendidas también como salvaguarda de lo valioso adquirido con la experiencia acumulada a lo largo del tiempo ${ }^{8}$. En este sentido, una de las tensiones sociales por excelencia, que es en el fondo la tensión de la vida, es esa que acabamos de mencionar (la tensión entre lo instituyente y lo instituido), de especial valía para entender el devenir histórico de esa institución que recoge en su seno todas estas tensiones intentando equilibrarlas —al menos en el proyecto ilustrado del que somos herederos-: el Estado.

Lo cierto es que esta tensión constitutiva, ineludible e imprescindible para explicar el proceso de construcción de la estructura política de la modernidad revolucionaria y su conversión en institucionalidad más o menos matizada, es

del Estado en América Latina. Perspectivas desde una epistemología del Sur. Lima, Instituto Internacional de Derecho y Sociedad/Programa Democracia y Transformación Global; (2011) El milenio Huérfano; Reinventar la democracia, reinventar el Estado Madrid, Trotta.

7 De manera muy clara y explícita se expone en Boaventura de Sousa Santos (1991) «Subjectividade, Cidadania e Emancipaçao» o.c.

8 No es ni mucho menos la única, pero sí una de las más ilustrativas, la referencia a la trilogía de Eric Hobsbawm al respecto de la fragua de la modernidad en muy similares términos: (2001) La era de la Revolución 1789-1848; (1998) La era del Capital. 1848-1875; (1998) La era del Imperio. 1875-194. Barcelona, Crítica. 
también la que permite explicar su derrumbe en cuanto se disuelve, no sólo deshaciendo el paradigma, sino también rompiendo el contrato social moderno. Veremos enseguida los detalles de este proceso del que aquí sólo podemos ocuparnos en sus rasgos mayores.

Quizá sea esta elección nuclear la razón por la que nuestro autor piensa de forma concomitante, como indisolubles, Democracia y Estado. O puede también ser debido a que el objeto de análisis es precisamente el proyecto político de la modernidad europea y sus peripecias, no siempre agraciadas. Según el diseño de ese proyecto, no es necesario reparar demasiado en que Estado y Democracia no son indefectiblemente dos conceptos que se reclamen recíprocamente. Por lo tanto, se postula que pensar el Estado se hace pensando la Democracia porque no hay otras formas de Estado admisibles - ni, seguramente, deseables-. Se da por sentado que esa es una de las claves liminares que enmarcan la reflexión de la que aquí nos hacemos cargo?.

Decíamos entonces que el eje que vertebra toda la reflexión sobre el Estado es la tensión entre lo instituyente (emancipación) y lo instituido (regulación) y que su disolución supone el colapso del sistema socio-político sostenido sobre esa viga maestra ${ }^{10}$. Según muestra Boaventura de Sousa Santos, nuestro momento histórico está marcado por la inercia de un paradigma, el de la modernidad política ligada sobre todo a Rousseau —su gran referente-, que está acabado porque ha disuelto esa tensión constitutiva moviéndose hacia el polo de la regulación (prescindiendo de cualquier posible Aufhebung hegeliana así como de toda dialéctica negativa que hubiese optado por mantener la tensión lo más viva posible), pero también por la emergencia de un nuevo paradigma político (del mismo modo también de carácter social, como vemos por recientes estudios que no dejan de destacar la desigualdad y la desaparición de eso llamado «cohesión social» propio de los estados sociales) que, todavía balbuceante, está lejos de lograr una formulación cabal y articulada, si bien va dejando ver ya con cierto grado de consistencia sus líneas maestras ${ }^{11}$.

\footnotetext{
9 Además de las propias obras de Boaventura de Sousa Santos, algunos textos de Jesús Aguiló Bonet abordan ese estudio de forma específica.

10 No es objeto específico de consideración en este texto, pero nuestro autor señala que esta línea de tensión visible está sostenida por otra tensión invisible de vital importancia: «He caracterizado la modernidad occidental como un paradigma socio-político fundado en la tensión entre regulación social y emancipación social. Esta es la distinción visible que fundamenta todos los conflictos modernos, en términos de problemas sustantivos y en términos de procedimientos. Pero por debajo de esta distinción existe otra, una distinción invisible, sobre la cual se funda la anterior. Esa distinción invisible es la distinción entre sociedades metropolitanas y territorios coloniales. En efecto, la dicotomía regulación/emancipación solo se aplica a las sociedades metropolitanas. Sería impensable aplicarla a los territorios coloniales. La dicotomía regulación/emancipación no tuvo un lugar concebible en estos territorios. Allí, otra dicotomía fue la aplicada, la dicotomía entre apropiación/violencia, la cual, por el contrario, sería inconcebible si se aplicase de este lado de la línea.» Cf. BoaventuRA DE Sousa SANTOS (2010), Descolonizar el saber reinventar el poder. Montevideo, Trilce, p. 30.

11 En este punto no puedo dejar de referirme al magnífico texto de WENDY Brown (2015), Undoing the Demos. Neoliberalism's Stealth Revolution. New York, Zone Books, en el que
} 
En este marco de referencias y con estas líneas maestras, la propuesta teórica y analítica de nuestro autor en torno al Estado se despliega en dos momentos. En el primero de ellos, el más amplio y de mayor hondura conceptual y analítica, se desarrolla una suerte de examen genealógico de la forma moderna del Estado que nos permite trazar un camino desde su constitución a su ruptura por implosión del contrato social de la modernidad. Ese colapso se produce por un desarrollo hipertrófico de la regulación que embrida la emancipación hasta ahogarla, rompiendo la línea de fuerza que mantenía en pie el edificio. Dice expresamente Boaventura de Sousa que «dejó de ser posible concebir estrategias emancipatorias genuinas en el ámbito del paradigma dominante, ya que todas ellas están condenadas a transformarse en otras tantas estrategias reguladoras $»^{12}$

En un segundo momento, Boaventura de Sousa Santos pasa a exponer las dificultades a las que se enfrenta el paradigma emergente, así como apuntar algunas de las características que podrían componer una nueva forma de arquitectura política con un Estado pendiente del mantenimiento de la tensión emancipatoria y el cuidado de sus espacios propios y apropiados. Se trata por tanto de una visión contra-hegemónica del Estado que, en mi opinión, pretende corregir los desvaríos del proyecto político de la modernidad, sobre todo en su fijación en estructuras híper-reguladas de representatividad, salvando lo que en ese proyecto era y es irrenunciable: el ideal de la emancipación, de la autonomía, la «salida de la autoculpable minoría de edad» a la que se refería Kant o el «caminar erguido» de Ernst Bloch ${ }^{13}$.

La exposición que sigue se atendrá a este proceder del autor para mostrar tanto el diagnóstico como la mirada hacia las emergencias que apuntan hacia un Novum todavía en estado de latencia pero que empieza a dar muestras suficientes de sus pretensiones e intenciones, que buscan dar cabida a lo mejor del proyecto moderno todavía no realizado y remodelado por el aprendizaje del «sur». Se trata, por tanto, de una teoría que es consciente de su carácter «utópico» en el más genuino y mejor sentido del término en la filosofía política contemporánea, especialmente en el sentido blochiano de la «utopía concreta», que identifica latencias en el seno de las sociedades y su historia buscando impulsarlas hacia lo mejor de sí mismas.

realiza un pormenorizado estudio del modo en que los discursos que englobamos dentro de la denominación "neoliberalismo» van erosionando los pilares fundamentales sobre los que se han asentado nuestras estructuras políticas y sociales desde los tiempos de las revoluciones francesa y americana. Este nuevo discurso político de insidiosa penetración va dejando ver ya con cierta nitidez sus líneas de fuerza, destacando el modo de operar de esa nebulosa constelación de contornos variables y escurridizos pero de probada eficacia corrosiva. Para un desarrollo histórico de las líneas de pensamiento neoliberal puede verse DAVID HARveY (2005), A Brief History of Neoliberalism. Oxford, Oxford University Press.

12 Boaventura de Sousa Santos (2003), Crítica de la Razón Indolente... p. 14.

13 Cf. Idem, Tercera Parte, pp. 293-438 
2. El Estado Distendido: El ADIÓS AL CONTRATO SOCIAL DE LA MODERNIDAD

Como venimos apuntando, la idea central que se enuncia es que la tensión inherente al proyecto político de la modernidad, y esencialmente constituyente para el mismo, es la tensión entre la emancipación (expresada sobre todo en los diferentes procesos revolucionarios de segunda mitad del siglo XvIII en adelante) y la regulación, congénita a la concreción institucional de lo anterior. El problema radica en que desde el principio casi, en ese proyecto la emancipación social devino gradualmente regulación (en lugar de mantenerse como su opuesto): «la hegemonía del conocimiento-regulación significó la hegemonía del orden, en tanto que forma de saber, y la transformación de la solidaridad - la forma de saber del conocimiento-emancipación - en una forma de ignorancia y, por tanto, de caos» ${ }^{14}$.

El orden del que se hablaba y que se buscaba desde el inicio del proyecto moderno se concibió simultáneamente como orden natural y social, en tensión dialéctica a su vez con la solidaridad, que es el principio básico que sostiene a la comunidad. El modo de proceder a la supresión del polo dialéctico solidaridad-comunidad fue simplemente la aplicación de la más elemental estrategia dialéctica: una nueva síntesis. En este caso, la síntesis ofrecida fue la idea del «buen orden». Y, una vez suficientemente arraigada esa idea, el buen orden generó la idea de orden tout court. ${ }^{15} \mathrm{~A}$ esta corriente no es en absoluto ajena la idea hegeliana del Estado como regulador que impone un orden superior a una sociedad civil que todavía no es capaz de pensar más allá de los intereses propios de grupo o clase. La cientifización del derecho en la modernidad es el modo en que éste se estataliza convirtiéndose en el instrumento mediante el cual el Estado cumple su tarea primordial: sostener el predominio político del orden sobre el caos mientas la ciencia y la tecnología no fuesen capaces de asegurarlo por sí mismas ${ }^{16}$.

¿Cómo se produjo ese desplazamiento que terminó por ahogar el impulso emancipador tan presente en el proyecto político moderno reduciéndolo a mero orden social? Según explica Boaventura de Sousa Santos, ese proyecto está formado, en el pilar de la regulación, por tres ingredientes principales: el Estado (tratado sobre todo por Thomas Hobbes), el Mercado (asumido como actor político por excelencia en la obra de John Locke) y la Comunidad (teorizada sobre todo en la obra de Jean Jaques Rousseau). En el polo de la emancipación se daban cita tres dimensiones de la racionalización y secularización de la vida colectiva: la racionalidad moral-práctica del derecho moderno, la racionalidad cognitivo-experimental de la ciencia y la técnica modernas y la racionalidad estético-expresiva de las artes y la literatura modernas. Es obvio que el equilibrio pretendido entre ambos polos dialécticos se obtiene mediante el desarrollo

14 Idem, p. 133.

15 Cf. Idem, pp. 133-134.

16 Cf. Ibídem. 
armonioso de cada uno de los pilares y de las relaciones dinámicas entre ellos. Es igualmente obvio que nunca se ha logrado tal equilibrio. A medida que la trayectoria de la modernidad se identificó con la trayectoria del capitalismo, el pilar de la regulación fue paulatinamente fortalecido a costa del progresivo debilitamiento del pilar de la emancipación y en una operación de reducción de sus principios constituyentes, como enseguida mostraremos ${ }^{17}$.

En el origen del paradigma, los tres ingredientes del pilar de la regulación estaban en pie de igualdad, sosteniendo una propuesta de organización social y política que prometía, al menos sobre el papel, el desarrollo equilibrado, paralelo e imbricado de todos ellos. La prueba de la complejidad que albergaba esta tríada queda bien recogida en el Derecho, el cual se presenta también con una triple faz: es voluntad del soberano (Hobbes) al tiempo que manifestación del consentimiento de los ciudadanos (Locke) y una clara auto-prescripción $\left(\right.$ Rousseau $\left.{ }^{18}\right)$, lo cual garantiza que la regulación se haga en nombre y en aras de la emancipación.

Tras su constitución más o menos lograda en el siglo XVIII, esta tríada pasará su prueba de fuego cuando tenga que confrontarse con la dura realidad en el siglo XIX, auténtico campo de pruebas real del paradigma de la modernidad, al menos en lo que respecta a los campos político y jurídico. Ahí aparece claramente configurado un nuevo elemento, el capitalismo, que se impone como la forma de producción dominante, asociada a la clase hegemónica del momento, la burguesía. A partir de ese punto, el paradigma político de la modernidad y el capitalismo se funden en una unidad que sólo recientemente comienza a mostrar fatiga estructural. La irrupción de este nuevo elemento supuso la generación de un desequilibrio en el pilar de la regulación que consistió, en términos generales, en el desarrollo hipertrofiado del principio de mercado en detrimento del Estado y en el desarrollo de ambos en detrimento del principio de Comunidad. Por supuesto no es un proceso histórico lineal sino más bien tentativo, que se despliega en fases en las que se van modelando mutuamente las hegemonías de los dos primeros con una única constante: el paulatino y eficaz desplazamiento del principio de Comunidad y, junto a él, la creciente desactivación de los mecanismos de emancipación ${ }^{19}$.

17 Cf. Boaventura de Sousa Santos, «Subjectividade, Cidadania, Emancipaçao»... p. 136.

18 Cf. Boaventura de Sousa Santos (2003), Crítica de la Razón Indolente... p.144: «En mi opinión, Rousseau representa el clímax de la concepción alargada de la racionalidad moral práctica, originalmente inscrita en el paradigma de la modernidad: la idea de una tensión creativa entre regulación y emancipación, que asume su forma política más concreta en la Declaración de los Derechos del Hombre y del Ciudadano (1789). La idea de Rousseau de un nuevo principio social y político, expresada en el Contrato Social y en otras obras de carácter político, muestra mejor que cualquier otro concepto iluminista la complejidad dilemática de una regulación social tendente a fomentar, nunca a sofocar, la emancipación prometida por la modernidad. Esta regulación social debería equilibrar la libertad y la igualdad, la autonomía y la solidaridad, la razón y la ética, la autoridad y el consentimiento, en nombre de una racionalización plena de la vida colectiva e individual.»

19 Cf. Boaventura de Sousa Santos, «Subjectividade, Cidadania, Emancipaçao... p. 137. 
Para dar cuenta del proceso de esta fusión, Boaventura de Sousa Santos menciona tres períodos históricos perfectamente identificables y rastreables. El primero de ellos es el denominado capitalismo liberal. Se trata de un momento en el que parece quedar claro que el proyecto político elaborado durante los dos siglos anteriores es demasiado ambicioso y, sobre todo, alberga contradicciones internas que se pueden agudizar según intereses de parte. El período siguiente, segundo de la serie, se conoce como el del capitalismo organizado. En este momento se cumplen algunas de las promesas de emancipación contenidas en el proyecto moderno inicial y, usando políticas de hegemonía, minimiza sus fracasos para invisibilizarlos social y políticamente. Se trata entonces de toda una operación de cirugía estética en la que simplemente se focaliza la atención sobre el desarrollo económico y el incremento de la riqueza, por ejemplo, obviando el costo social a su vez generado por las dinámicas propias del mercado y sus exigencias. Finalmente, el tercer y último período, en el que de hecho nos hallamos, es el capitalismo desorganizado. En él se considera que lo realizado/logrado en la modernidad no es irreversible, lo cual viene siendo una declaración de obsolescencia y una propuesta de "superación» simultáneamente. Se dice además que lo incumplido seguirá disfrutando de tal condición mientas el paradigma no cambie. Obviamente esto abre las puertas a un tipo de cambio que recupere la emancipación no realizada o malograda, pero también abre la posibilidad a la implantación de un sistema de organización social y política en la que los anhelos de emancipación, si no quedan desterrados, al menos resulten inoperantes o inocuos, de modo que se vean como mero ejercicio de nostalgia y/o simple reminiscencia de tintes folclóricos. Lo que oculta este último estadio de desarrollo es que el déficit emancipatorio es mucho mayor de lo pensado en el período anterior, y que, además, es tristemente irreversible.

La referencia a este devenir histórico de la relación entre estos tres principios del proyecto moderno se ha ceñido a una somera descripción de lo que nos interesa en términos de la tensión central y sostenedora del mismo. En esta deriva, y desde el primer período, dos elementos se enfrentan en un juego que poco a poco va dominando el conjunto de la escena desplazando cualquier otro proceso dinámico que en ella pudiera comparecer. El Estado y el Mercado van generando su propia conversación dejando paulatinamente apartado al principio de la comunidad. Este principio, que en la obra de Rousseau es una realidad única y soberana, empieza a debilitarse seriamente cuando se hace pública y hegemónica la descripción hegeliana que divide y reduce la comunidad a familia, sociedad civil y estado, deviniendo estas «figuras» del desarrollo dialéctico del Espíritu, lo cual las vacía de realidad efectiva para ponerlas en el mundo de la abstracción.

Probablemente no es necesario ni pertinente ahora abundar en las difíciles relaciones entre Estado y Mercado y el modo en que ambos han ido dibujando los contornos de las formas políticas hoy tan familiares y naturalizadas en nuestras arquitecturas sociales. Baste señalar para nuestros propósitos la precisión del vaticinio de Emile Durkheim según el cual, el desarrollo de las relaciones de mercado implicaría un desarrollo de las relaciones estatales. El 
modo de desplegar esta curiosa forma de simbiosis antagónica es lo que nuestro autor llama el Absolutismo Jurídico, cuyo epítome es el desarrollo del derecho privado ${ }^{20}$.

Lo que interesa entonces es ver de qué forma ese tercer principio, el de la comunidad, va siendo paulatinamente desplazado, especialmente en el siglo XIX, sobre todo en su segunda mitad. Hay dos motivos que impelen la transformación de la distinción entre sociedad civil y Estado en ese período histórico. Por un lado, se aprecia la necesidad de un incremento de la gestión pública de la economía, acompañada o más bien urgida por la creciente complejidad del capitalismo naciente en su rápida expansión colonial y los cada vez más amplios procesos de industrialización. Por otro lado, es cada vez más evidente el proceso de convergencia entre los intereses del Estado y los de las grandes empresas, hasta el punto de resultar indiscernibles en términos económicos y, en consecuencia también, en términos jurídicos.

Ese período del capitalismo organizado es fundamental en la configuración de esta relación en apariencia simbiótica entre Estado y Mercado, que pronto se revelará parasitaria. No en vano es el momento en que con fuerza aparece la tristemente famosa «cuestión social». La manera de afrontarla y plantearla es a través del desarrollo de la ordenación de las relaciones laborales, el planteamiento de la ordenación del territorio y la planificación urbana. Es interesante observar cómo en este encuentro entre Estado y Mercado se produce esa forma política nueva que se dio en llamar el «Estado-Providencia» (entre otras nomenclaturas), de manera que los conflictos entre ambos principios no se cronificasen y se resolviesen de forma institucional además de parcializarse y localizarse en sectores concretos impidiendo la afectación sistémica total. La importancia de este movimiento radica en que se fortaleció igualmente el principio de comunidad. El carácter distributivo de las políticas sociales del Estado-Providencia se fundamenta sobre la noción de solidaridad, esto es, una relación de reciprocidad horizontal ${ }^{21}$, de ciudadano a ciudadano, que es el núcleo central del principio de comunidad. Eso sí, este principio no fue reconocido en sus propios términos. Más bien estamos ante una derivada de la relación entre Estado y Mercado bajo la égida del primero.

En este punto, el diálogo tripartito inicial propuesto por el diseño político de la modernidad revolucionaria ya se ha decantado en un dúo en el que el principio de comunidad se ve reconsiderado y deviene simple «cuestión» que tanto Estado como Mercado deben gestionar de la forma más satisfactoria posible para sus intereses. Intereses que a estas alturas resultan, cuando menos,

20 Cf. Boaventura de Sousa Santos (2003), Crítica de la Razón Indolente... p. 164 ss.

21 Este sería el contexto en el que ubicar la famosa conferencia de T. H. MARSHaLL (1949) titulada Ciudadanía y Clase Social en la que precisamente se plantea esa relación de reciprocidad horizontal. Algunos años más tarde, en la década de los 70, el propio Marshall se desdijo de este planteamiento, situando al Mercado y sus intereses en el lugar de preminencia, rompiendo así el pacto de reconocimiento de los derechos sociales y económicos que fundaba el Estado Social. 
concomitantes. ¿Cómo se opera esa reducción de principio a cuestión? Mediante un eficaz truco, fruto a su vez de la regulación puesta en marcha en nombre de la emancipación. El truco consiste en sustituir esa relación horizontal de solidaridad que vincula a la comunidad por una doble relación vertical que introduce una división interna en la comunidad obligándola a mirar a un tercero: la relación entre el Estado y los contribuyentes, y el Estado y los beneficiarios de políticas sociales. Obviamente, esta reconfiguración de las relaciones intracomunitarias en función de una diferencia en el modo de relación con el Estado (ni todos son meramente beneficiarios ni todos meramente proveedores, sino más bien ambas cosas al mismo tiempo con respecto al Estado) introduce un antagonismo (en ningún caso desinteresado ni tampoco inocente, mucho menos inocuo) que termina por romper cualquier brote de relaciones horizontales de solidaridad igualadora porque siempre prima la diferencia que acabamos de mencionar. El truco del trilero que pone el acento y la bolita en otro sitio es de una eficacia abrumadora y, a la larga, destructora de la dinámica ordenadora, destinada por su propia tensión interna a desaparecer. El interés por conciliar y equilibrar, que es el fin más destacado de este período, implicaba, de forma tácita, reducir las pretensiones de emancipación a unas dimensiones realistas asumidas en soluciones de compromiso de carácter meramente coyuntural que, a la larga, sustituyeran a los principios. Así, «solidaridad, justicia e igualdad podían ser compatibles con autonomía, identidad y libertad, siempre que cada conjunto de valores, aparentemente incompatibles, fuese reducido a lo que era realistamente exigible en una sociedad capitalista ${ }^{22}$. Es decir, se trababa de hacer plausible la promesa de una distribución intencionalmente más justa de los bienes y la promesa de una creciente - y por qué no, imparable también- democratización del sistema político. Por razones obvias, este matrimonio imposible supuso el triunfo del reformismo sobre la revolución, tal como el declive de las posiciones ideológicas de la izquierda marxista y socialista (luego reconvertida a social-democracia) se han encargado de atestiguar.

Lo que ocurre en el período que Boaventura de Sousa Santos ha denominado "capitalismo desorganizado», etapa inmediatamente posterior a la que acabamos de presentar, es un «suma y sigue» en esta dinámica que venimos describiendo. Se le llama «desorganizado» no porque sea caótico en sí, que en absoluto lo es, sino porque implica y significa el desmantelamiento rápido, urgente, de las formas de organización social que se asentaron en el período anterior. De hecho, podría decirse que, casi de forma paradójica, en esta nueva etapa el capitalismo está más organizado de lo que lo ha estado nunca. Eso sí, desacoplándose de los canales estatales que le obligaban a no dañar en exceso el entramado social. Ese desmantelamiento, como no podía ser de otro modo, está acompañado por la sustitución de los modelos organizacionales del Estado-Providencia por otros nuevos capaces de dominar todos los aspectos de la vida social y, a la vez, duchos en la tarea de neutralizar a sus opositores

22 Boaventura de Sousa Santos, Crítica de la razón indolente... p. 168. 
tradicionales. A nadie escapa que esta es una forma elegante de describir precisamente el momento histórico que estamos viviendo.

Según la descripción de nuestro autor, se trata de un (¿interminable?) período de transición entre regímenes de acumulación pero, sobre todo, una transición entre un modelo de organización de la sociedad a otro, todavía provisional y con contornos difusos, pero que ya apunta a una «superación» del estado democrático de derecho. Este inquietante diagnóstico ${ }^{23}$ se verifica cuando observamos cómo, lo que fueron consideradas conquistas asentadas - la promesa de más justa distribución de los beneficios sociales en pro de la igualdad y la promesa de un sistema político con cierta estabilidad y cierto nivel democrático- no sólo no han tenido continuidad sino que han ido sufriendo una paulatina y eficaz erosión desde los años 80 del pasado siglo: desigualdad creciente, aumento de la pobreza, crecientes dinámicas de exclusión social dentro de las economías desarrolladas, recortes paulatinos de las políticas sociales, deslegitimación del Estado como institución política, corrupción, populismos, cuestionamiento de los mecanismos de representación y de la representación misma, etc. El panorama se completa con la desactivación de los dos mecanismos de transformación social vigentes desde la segunda mitad del siglo XviII: la revolución y la reforma. La revolución dio sus últimas muestras de agotamiento en los países periféricos que la intentaron en el último tercio del pasado siglo, y la reforma, muy ligada a la social-democracia, sufre una considerable pérdida de vigor tan grave como la que afecta al Estado-Providencia y la incapacidad de la propia social-democracia para promover alternativas políticas eficaces.

Según este análisis, en esta última etapa las mayores transformaciones sociales y políticas están lideradas por el Mercado. Este pilar del proyecto político de la modernidad europea ha sido capaz de ocupar prácticamente todo el espacio de la regulación mediante la producción de un exceso de sentido que ha sido capaz de invadir - hasta casi hacerlos desaparecer por inoperantes- al Estado y a la Comunidad. Ese proceso multifacético que llamamos Globalización ha proporcionado los mecanismos para el asentamiento de esa hegemonía: mercados financieros mundiales que no dejan de operar a lo largo del día, sistemas de producción igualmente mundial, agentes económicos internacionales con un poder mayor que el de muchos estados, la creación de un doble régimen jurídico (uno para bienes y mercancías —especialmente el dinero- y otro para la circulación de personas) han logrado romper el molde espacio-temporal en el que se han movido hasta ahora las relaciones humanas a cualquier nivel. Por supuesto, las que aquí más nos atañen, las políticas y económicas han sufrido esta expansión extensiva del mercado y su lógica ligada al consumo, la obsolescencia y la competitividad.

En este contexto, el Estado pierde su estatuto de unidad de análisis privilegiada en la escena política y en lo referente a la práctica social. Es un diagnóstico compartido por todos los analistas de la Globalización la crisis del

${ }^{23}$ Cf. Idem, pp. 173-74. 
Estado-nación como actor en el actual sistema mundial de relaciones internacionales. Al perder protagonismo, porque el concepto de soberanía se erosiona tanto a través de la pérdida de poder económico como en la pérdida de legitimidad al interior de la sociedad, el Estado pierde también capacidad de acción en las políticas sociales. Así aparecen fenómenos como la desregulación, la privatización, la coparticipación en los costos, etc., apuntan precisamente en esta dirección.

$¿$ Y la Comunidad? Este principio, nunca suficientemente desarrollado desde el inicio del proyecto político de la modernidad, retrocedió todavía más que en las etapas anteriores. Como vimos, en el período anterior la introducción del Estado como mediador entre el contribuyente y el beneficiario de las políticas sociales modificó, hasta impedir su reconocimiento, el sentido de solidaridad horizontal constituyente y constitutivo de cualquier comunidad. En este nuevo período se intensifican las prácticas destinadas a neutralizar los mecanismos de agregación y solidaridad horizontal: la precarización salarial, la segmentación del mercado de trabajo, la jerarquización obrera, el incremento del desempleo y del sub-empleo o empleo precario que ni siquiera permite superar los umbrales de la pobreza... En definitiva, se produce una ruptura con el paradigma de los derechos reduciendo al ciudadano a la mera condición de cliente/consumidor (ni siquiera ya productor) o, todavía peor, a la condición de expulsado del sistema social.

Todo este proceso, descrito en sus líneas de fuerza y sin entrar en mayores precisiones, supuso a su vez tres movimientos relevantes en la tensión emancipación-regulación que venimos considerando clave de la construcción socio-política de la modernidad. El primero de esos movimientos queda enmarcado dentro de la forma política del Estado liberal. En él la emancipación se subordina a las exigencias de los Estados y se adscribe, por antonomasia, a los movimientos revolucionarios. Por así decirlo, deviene el comienzo de una nueva regulación que colmaría las aspiraciones de la autonomía. El segundo movimiento se corresponde con la etapa del Capitalismo Organizado en el que se asume que el proyecto emancipador es compatible tanto con la producción y la reproducción social del orden vigente (obviamente, el capitalismo), lo cual implica una criba del ideal emancipatorio en términos de rebaja. Finalmente, el tercer movimiento, encuadrado dentro de lo que hemos llamado capitalismo desorganizado, de hecho supone la mutua desintegración de regulación y emancipación porque se desmantela el régimen social (es decir, el orden establecido) vigente en y desde la etapa anterior. Y surge aquí una importante novedad que afecta al modo en que la teoría política desde Hegel ha venido pensando la estructura básica de la sociedad política:

«La dicotomía Estado/sociedad civil ocultó la naturaleza de las relaciones de poder en la sociedad y es indiscutible que el derecho contribuyó decisivamente a ello. La concepción del poder del Estado como la única forma de poder político-jurídico no significó que no hubiese otras formas de poder en la sociedad; más bien los convirtió en poderes fácticos sin base jurídica autónoma y, en todo caso, sin algún carácter político. Si consideramos las 
relaciones de poder realmente existentes en las sociedades del inicio del siglo XIX, la reducción del poder político al poder del Estado nada tiene de obvio. Sin embargo, permitió pasar de las promesas emancipadoras globales, inscritas en el paradigma de la modernidad, a la promesa de la democratización del Estado. A partir de ahí, la forma de poder estatal, más o menos democrática, puede coexistir con formas más o menos despóticas de poder social sin que la naturaleza democrática del sistema político fuese puesta en cuestión» ${ }^{24}$.

Esta es, ni más ni menos, que la dinámica de la mal llamada «desregulación» que ha sabido ser muy bien aprovechada para la instauración de un orden social de características ciertamente despóticas pero muy favorecedoras de intereses muy fuertes provenientes de una parte de la sociedad civil que han logrado imponerse mediante la absorción del Estado por aquella y viceversa. Es decir: el Estado reproduce a la sociedad civil y esta reproduce a su vez al Estado. En opinión de Boaventura de Sousa Santos, esta recíproca dinámica de absorción y reproducción es lo que permite explicar que la mayor parte de las propuestas para dotar de mayor poder a la sociedad civil frente al Estado redunden en un creciente desarme social y político de los ciudadanos: el poder que supuestamente se quita al Estado para darlo a la sociedad civil en realidad continúa siendo ejercido bajo la tutela última del Estado, si bien el actor ya no es la administración pública sino las organizaciones privadas, lo cual hace desaparecer el control democrático sobre las acciones porque las organizaciones privadas no están sujetas a él. Obviamente, la lógica privada (que casi siempre es la del afán de lucro) combinada con la ausencia de controles democráticos — pues los actores privados no están sometidos a ellos- derivan en el agravamiento de las desigualdades sociales y políticas propias de la época que nos toca vivir ${ }^{25}$.

\section{VÍAS PARA LA REINVENCIÓN/REFUNDACIÓN DEL EsTADO}

Tras lo expuesto, parece sencillo deducir que la parte propositiva de la teoría de Boaventura de Sousa Santos en lo tocante al Estado tiene como objetivo no sólo recuperar la tensión entre lo instituyente y lo instituido, sino hacerlo de modo que aparezca por fin como elemento clave y esencial del polo regulador el principio de comunidad (que en su diversidad e interna pluralidad es la avanzadilla de la emancipación en la regulación), a su vez capaz de rescatar al «Estado» como institución política si ne qua non. Y se trata de hacer esto con cierto tono de urgencia, pues estamos en una situación de gravedad que algunos califican de cercana al borde del abismo y es necesario un freno y luego un

24 Idem. pp. 197-198.

25 Cf. Ibidem. 
proceso de recreación de un nuevo proyecto socio-político ciertamente emancipador para estar a la altura de lo humano ${ }^{26}$.

El abordaje de este ambicioso proyecto de refundación del Estado, la Emancipación y la Comunidad (en su expresión democrática) parte de la constatación de una serie de dificultades de diversa índole y grado. Boaventura de Sousa Santos enumera siete: la primera supone vencer la tentación de eliminar el Estado como institución reconociéndole capacidades de ingeniería social que, por sí solas, ya justifican la teoría política de su refundación. La segunda dificultad radica en el hecho de que la larga duración histórica del Estado ha hecho que esté presente en la sociedad mucho más allá de su mera institucionalidad - tal como vimos al describir la circularidad entre Estado y Sociedad civil-, lo cual hace ver que su refundación no es sólo una tarea política sino también social, cultural, simbólica, que implica mentalidades, hábitos y subjetividades, con el ánimo de establecer una nueva y diferente hegemonía. La tercera dificultad implica la aparición de un nuevo sujeto de transformación: no serán sólo los grupos oprimidos quienes realicen esa transformación, sino que es necesario crear alianzas con grupos y clases sociales más amplios. La cuarta dificultad es que la refundación del Estado exige, en el actual contexto mundial, un diálogo intercultural que movilice universos culturales diferentes y diferentes conceptos de tiempo y de espacio, lo cual exige, a modo de condición previa, un diálogo basado en el mutuo reconocimiento superador de una historia de choques y desprecios, capaz de motivar la convergencia de voluntades políticas muy diferentes, que se han formado en el contexto que acabamos de mencionar. La quinta dificultad estriba en que la refundación del Estado no requiere sólo una modificación de su estructura institucional o su arquitectura política organizacional, sino sobre todo y en primera instancia impele un cambio en las relaciones sociales y la cultura, especialmente en lo concerniente a la economía y sus modelos vigentes. Una sexta dificultad descansa en la cuestión indígena, pues es un proyecto de alcance global y es imprescindible dar con un modo de relación en el que sea posible el encuentro (que no la imposición) entre formas de distribución y ejercicio del poder tan divergentes como las vigentes en las comunidades indígenas y las que plantea la institución del Estado. La séptima y última dificultad apuntada es la necesidad de superar, por un lado, el fracaso estrepitoso de la refundación más ambiciosa efectuada en el siglo pasado en el Estado soviético, así como por otro el intento reformista de la social-democracia igualmente fracasado en términos reales pero todavía con un fuerte peso en la imaginación emancipadora ${ }^{27}$.

26 Cf. Boaventura de Sousa Santos (2007), Reinventado la emancipación social, p.13, texto de una conferencia pronunciada en La Paz invitado por la Alianza Francesa que luego fue incluido en (2009) Pensar el Estado y la Sociedad. Desafíos Actuales. Buenos Aires, WaldhüterClacso, p. 18.

27 Cf. Boaventura de Sousa Santos (2010), Refundación del Estado en América Latina. Perspectivas desde una epistemología del sur. Lima, Instituto Internacional de Derecho y Sociedad, pp. 69-71. 
Semejante cúmulo de dificultades, sumado al grado que plantea cada una de ellas, solicita un esfuerzo de imaginación teórica y práctica similar al que se dio en el siglo xvIII, solo que en esta ocasión no contamos con un humus social y político tan activado como en el que se pudieron gestar las revoluciones francesa y americana, toda vez que tampoco tenemos a mano instrumentos tan eficaces como en su momento fueron la revolución y la reforma. Por otro lado, el propio autor es partidario de reconducir los procesos de racionalidad metonímica y proléptica propios de la razón indolente, para así ensanchar los límites del presente - contra la razón metonímica — y contraer el futuro entendido como simple proyección continuista del presente - contra la razón proléptica- $y$, de ese modo, poder pensar, con claves de una racionalidad cosmopolita, una arquitectura política estatal emancipatoria (y no es un oxímoron) ${ }^{28}$.

Es de esperar, por tanto, que esta nueva razón cosmopolita, apenas en sus albores, no disponga todavía de la capacidad analítica y propositiva de la razón indolente y, en consecuencia, disponga apenas de un puñado de intuiciones sobre los pasos que se pueden dar para encaminar el proyecto emancipatorio pendiente pero ya anunciado en la modernidad, solo a medias realizada. Exponemos esas intuiciones a continuación.

La primera de ellas es la necesidad de un nuevo tipo de constitucionalismo que nace "desde abajo», protagonizado por los grupos excluidos y sus aliados y que tiene entre sus objetivos la consecución de la plurinacionalidad, una nueva forma de territorialidad constituida por las autonomías asimétricas, la integración del pluralismo jurídico y el cuidado de la democracia intercultural que Santos denomina, con una expresión feliz, demodiversidad ${ }^{29}$. Esto nos avoca a una geometría variable de los Estados, la cual está marcada en cualquier caso por la generación de espacios en los que es posible la movilización social de carácter transformador y contrahegemónico. La desconstitucionalización de la Constitución sería ese mecanismo que genera un «afuera» de las instituciones en el que es posible alimentar la presión en contra de la hegemonía, imprescindible para mantener la tensión entre regulación y emancipación ${ }^{30}$.

La tercera intuición, característica de este proceso de transición paradigmática, es el experimentalismo. Hay que reconocer que el proceso de surgimiento de lo nuevo es, se mire como se mire, semiciego y semi-invisible, pues en primer lugar no hay recetas y, en segundo lugar, de muchas ideas no puede saberse a priori su funcionamiento real, así que no queda más remedio que ensayarlas. Por eso es imprescindible en esta etapa plantear procesos tentativos, soluciones revisables y evaluables y dejar cuestiones abiertas en debate

28 En diferentes lugares ha desarrollado su crítica a esta racionalidad indolente nuestro autor. Además de su Crítica a la Razón Indolente, ya citado, podemos referirnos al menos a estos otros lugares: Hacia una sociología de las ausencias y una sociología de las emergencias (véase nota 4) y, sobre todo, (2006) Conocer desde el Sur. Para una política emancipatoria. Lima, Fondo editorial de la Facultad de Ciencias Sociales, el capítulo 3, pp. 65-116.

29 Cf. Refundación del Estado en América Latina... pp. 71-72.

30 Cf. Idem, p. 80. 
y a la búsqueda de nuevas claves. Esto exige mecanismos constitucionales de reforma y adaptación ágiles y eficaces capaces de reconocer la transitoriedad de las soluciones tanto por razones técnicas como por razones políticas (atendiendo a su vez a la velocidad con la que se producen cambios relevantes en las estructuras interdependientes globales), pues las inevitables tensiones del proceso pueden superponerse unas a otras sobrealimentándose o bien pueden neutralizarse ${ }^{31}$.

Finalmente, parece ineludible poner fin a eso que el propio autor ha denominado democracia de baja intensidad ${ }^{32}$ reemplazándola por su contrario, una democracia de alta intensidad. Esta forma de democracia (probablemente una de las pocas merecedora de tal nombre) requiere en primera instancia ciudadanos que lo sean, y para ello se precisa un amplio debate sobre participación política, la identidad y la cuestión de los derechos. Además se demanda un uso contra hegemónico de la democracia representativa, de manera que la representación no quede neutralizada por la desconexión técnica entre los órganos de representación y los ciudadanos, y se dé usando otro tipo de criterios - como por ejemplo cualitativos en lugar de los meramente cuantitativos-. Igualmente se hace necesario diseñar e implementar nuevas formas de participación política ciudadana que redunde directamente en la toma de decisiones, como el ejemplo de los presupuestos participativos ha mostrado en diferentes lugares del mundo. Y, por último, la recuperación y el cuidado compartido del espacio público y los bienes comunes.

Todo este programa lo condensa Santos al final de la conferencia titulada Reinventando la Emancipación Social, en los siguientes términos, que no nos resistimos a reproducir:

«En conclusión, lo que es diverso no es inconmensurable, lo que es unificado no es uniforme, lo que es igual no es idéntico, lo que es desigual no es necesariamente injusto. Tenemos el derecho a ser iguales cuando las diferencias nos hacen inferiores; tenemos el derecho a ser diferentes cuando la igualdad nos quita nuestras características en el continente. Hoy la identidad nacional no se puede analizar sin identidades transnacionales, continentales y también locales. La complejidad reside en que un miembro de una cultura dada solamente está dispuesto a reconocer a otra cultura si siente que su propia cultura es respetada, y esto se aplica tanto a las culturas indígenas como a las culturas criollas. El reconocimiento recíproco debe tener en cuenta el desconocimiento recíproco en el pasado y, como digo siempre, el desconocimiento de las injusticias históricas. Estas son tareas permanentes, pero una cosa es cierta: el Estado moderno y la democracia no van a crear un mínimo de estabilidad política, Por eso estamos en esta dualidad o dicotomía: o inventamos un Estado pluricultural y postcolonial, una democracia de alta intensidad

31 Cf. Idem, pp. 110-111.

32 Entre otros lugares, la usa en los siguientes escritos: (2004) Democratizar la democracia: los caminos de la democracia participativa. México, Fondo de Cultura Económica; (2005) El milenio huérfano. Madrid, Trotta; (2007) Globalización y Democracia en Archipiélago 73-74, pp. 111-125. 
intercultural y postcolonial o tenemos la barbarie, que puede ser peor que lo que tenemos hoy. Por todo eso debemos luchar con nuestras diferencias y con solidaridad, que el gran objetivo es evitar la fragmentación. El fraccionalismo de nuestras diferencias nos puede hacer vulnerables y volvernos a la barbarie. Eso es algo que no podemos tolerar» ${ }^{33}$.

Centro de Ética Aplicada

Javier Martínez-Contreras

Universidad de Deusto

javier.contreras@desuto.ed.

[Artículo aprobado para publicación en diciembre de 2015]

33 Reinventando la Emancipación Social, o.c., pp. 29-30. 